\title{
Fabricación y caracterización de conductividad térmica de materiales aislantes a base de fibras naturales
}

\section{Manufacture and characterization of thermal conductivity of insulating materials based on natural fibers}

\author{
Rolando Carvajal ${ }^{1}$, Angélica Chung ${ }^{2}$, Abdiel Pérez ${ }^{3}$, José Solís ${ }^{1}$, Nacarí Marín $^{4 *}$ \\ ${ }^{1}$ Licenciatura en Ingeniería Electromecánica, Centro Regional de Azuero, Universidad Tecnológica de Panamá \\ ${ }^{2}$ Licenciatura en Ingeniería Mecánica, Centro Regional de Azuero, Universidad Tecnológica de Panamá \\ ${ }^{3}$ Licenciatura en Ingeniería de Energía y Ambiente, Centro Regional de Azuero, Universidad Tecnológica de Panamá \\ ${ }^{4}$ Facultad Mecánica, Centro Regional de Azuero, Universidad Tecnológica de Panamá
}

\begin{abstract}
Resumen La eficiencia energética de una edificación puede mejorarse cuando se consideran durante su diseño y construcción materiales con propiedades de aislamiento térmico. En este trabajo se realizó un estudio de fabricación y de caracterización térmica de 3 materiales naturales, aglomerados con almidón de yuca. Las fibras utilizadas son catalogadas como desechos agroindustriales. Los materiales han sido estudiados mediante un prototipo de medidor de conductividad térmica, basado en la norma ASTM-C177 y en la Ley de Fourier de transferencia de calor por conducción.
\end{abstract}

Palabras clave Aislamiento térmico, conductividad térmica y materiales naturales.

\begin{abstract}
The energy efficiency of a building can be improved when materials with thermal insulation properties are considered during its design and construction. In this work, a manufacturing and thermal characterization study of 3 natural materials, agglomerated with cassava starch, was carried out. The fibers used are classified as agro-industrial waste. The materials have been studied using a prototype thermal conductivity meter, based on the ASTM-C177 standard and the Fourier law of conduction heat transfer.
\end{abstract}

Keywords Thermal insulation, thermal conductivity, natural materials.

* Corresponding author: nacari.marin@utp.ac.pa

\section{Introducción}

En el estudio de la eficiencia energética de una edificación se requiere considerar diferentes aspectos como la instalación de equipos, la orientación de la edificación, la temperatura exterior y los materiales de construcción, por mencionar algunos. Durante los últimos años este tema ha cobrado interés, considerando el alto consumo de energía eléctrica en Panamá [1]. En la Estrategia Nacional de Cambio Climático de Panamá (ENCCP), se expone la importancia del desarrollo de estrategias y el desarrollo de capacidades para mitigar el cambio climático [2], considerando que el uso inadecuado de la energía repercute directamente en el ambiente. La temperatura exterior e interior en un recinto son datos que pueden ser utilizados para conocer la situación actual y reacondicionar un recinto, para un mejor aprovechamiento de la energía [3], [4]. Los materiales con buenas propiedades como aislamiento térmico se incluyen como una alternativa, gracias a la capacidad que tienen estos de reducir la transferencia de calor por conducción de un punto a otro, evitando así las pérdidas de energía [5], [6] y un menor consumo de la energía eléctrica.

El objetivo principal de este artículo es evaluar y analizar el desempeño de materiales naturales a partir de la medición de su conductividad térmica, mediante su estudio a nivel teórico y de ensayos prácticos para la identificación del potencial de aislamiento térmico de un recinto [7]. En este proyecto se utilizó como materiales naturales la paja de arroz, tusas de maíz, estopa de coco y bagazo de caña. Para cada uno de estos casos se empleó el almidón de yuca por su alto contenido de amilosa y amilopectina, moléculas que dan como resultado la propiedad de adhesividad [6].

\section{Fabricación de paneles de materiales naturales}

La reutilización de materiales para el aprovechamiento de recursos que normalmente son considerados como desechos, justifica el estudio desde el punto de vista de búsqueda del valor agregado de materiales que normalmente son 
considerados como desechos de procesos industriales y agroindustriales. En este proyecto se identificaron los materiales como la paja de arroz, bagazo de caña y fibra de coco, utilizando como aglomerante el almidón de yuca, debido a su buena propiedad de cohesión y adhesión con otros materiales.

Las placas de materiales son realizadas en un molde de madera que cumple con la medida mínima de la norma ASTM177 (30 cm de ancho, $30 \mathrm{~cm}$ de largo y $1.5 \mathrm{~cm}$ de espesor) [1]. Detallamos el proceso de fabricación de los paneles a base de material natural estudiados.

\subsection{Paja de Arroz y almidón de yuca}

La obtención de este material fue a partir de la paja de arroz, que puede clasificarse como desecho, que no se utiliza; una vez cosechado el arroz. Se procedió a recolectar suficiente material para la obtención de una placa de este material, mezclándolo con almidón de yuca [2]. El proceso de mezcla de este material fue netamente artesanal. Utilizamos $405 \mathrm{~g}$ de paja de arroz y $210 \mathrm{~g}$ de almidón de yuca para obtener la placa de este material. Es decir, se utilizó $66 \%$ de paja de arroz y $34 \%$ de almidón de yuca. Una vez mezclados ambos materiales, y puestos en un molde de madera, la placa se expuso al sol durante 2 semanas, como parte del proceso de secado.

\subsection{Bagazo de caña y almidón de yuca}

El bagazo de caña es producido a partir de la fabricación del azúcar, y se pude decir que es un subproducto que se puede utilizar como combustible natural para generar vapor en las fábricas donde se produce azúcar [3].Al igual que la paja de arroz, el bagazo de caña puede considerarse un desecho agroindustrial. La elaboración de la placa de este material, se tomó $300 \mathrm{~g}$ de bagazo de caña y $165 \mathrm{~g}$ de almidón de yuca. En términos de porcentaje, se utilizó $65 \%$ de bagazo y $35 \%$ de almidón de yuca como aglomerante para compactar el molde de este. El proceso de mezclado fue artesanal al igual que el de paja de arroz, por lo que se procedió a mezclarlo hasta obtener la masa necesaria para colocarla en el molde. Una vez puesto, se dejó secando al sol aproximadamente una semana y media.

\subsection{Estopa de coco y almidón de yuca}

Es un sustrato que se obtiene de los residuos que produce el coco. Estas fibras tienen componentes como la celulosa y el leño, que le dan una buena rigidez y dureza [4]. Tiene como características principales la baja conductividad al calor, resistencia al impacto y a las bacterias, entre otras. Para la obtención de la placa de prueba para la medición de conductividad térmica, se tomó $300 \mathrm{~g}$ de estopa de coco y 153 $\mathrm{g}$ de almidón de yuca como aglomerante. En otras palabras, se usó $65 \%$ de fibra de coco y $35 \%$ de almidón de yuca. Una vez realizado, se colocó en el molde y se cumplieron los pasos para el proceso de mezclado y secado de este.

\section{Medidor de conductividad térmica}

El estudio de la conductividad térmica, se diseñó un prototipo basado en un método experimental para la medición de la conductividad térmica de los paneles fabricados. El equipo de medición de conductividad térmica consiste en un Arduino con un sensor DHT22, una cámara termográfica y una caja de madera de $30 \mathrm{~cm}$ de ancho por cara, $30 \mathrm{~cm}$ de largo por cara y $1.5 \mathrm{~cm}$ de espesor con $2 \mathrm{~mm}$ de recubrimiento interior de fibra de vidrio. El tamaño de la muestra debe ser del tamaño de una cara de la caja de medición, es decir, de $30 \mathrm{~cm}$ de ancho por 30 $\mathrm{cm}$ de largo, y $1.5 \mathrm{~cm}$ de espesor, aproximadamente. El prototipo se basa en Ley de Fourier de transferencia de calor por conducción [5] y en la norma ASTM-C177 [1].

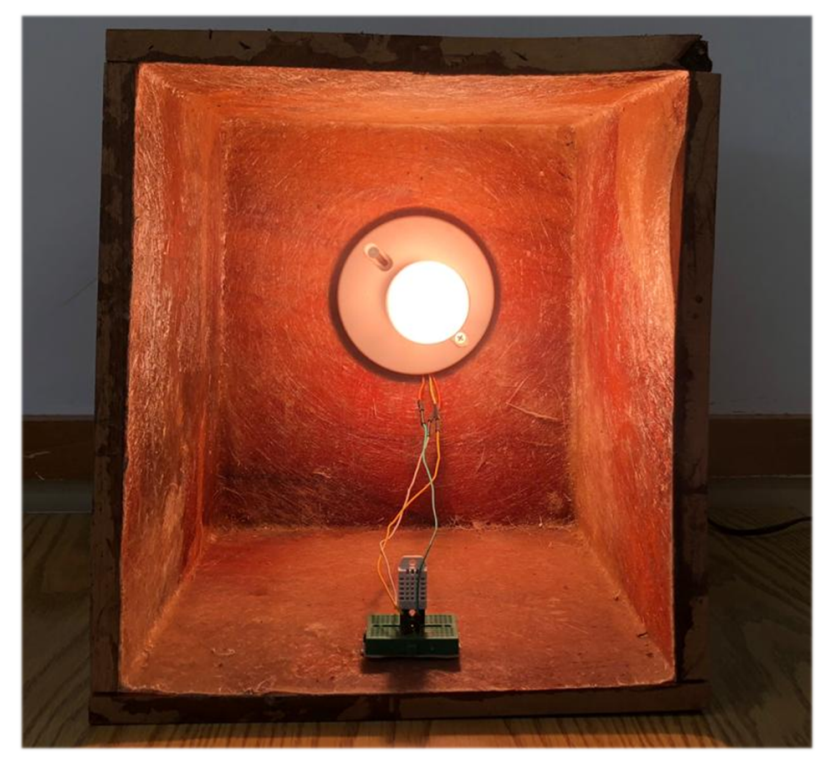

Figura 1. Medidor experimental de conductividad térmica.

En esta norma se establecen una placa con superficie caliente y dos placas frías. En la superficie caliente se tiene la zona de medida y su protección correspondiente y se pueden poseer uno o más calentadores. El objetivo principal del método es medir el gradiente de temperatura que hay dentro de la muestra. La temperatura superficial del método se mide con termopares montados en las placas superficiales. Se recomienda colocar un sensor de temperatura en el centro de la sección medida previamente. La medición de potencia, se utiliza un vatímetro o mediciones de voltaje y corriente.

En cuanto al equilibrio térmico, es necesario darle al sistema el tiempo necesario para alcanzar la estabilización de la temperatura. Una vez colocada la muestra, se procede a alimentar el equipo y encender las fuentes de calor, la cual debe ser, para este caso, un bombillo incandescente de cualquier valor de potencia que se encuentre disponible, como por ejemplo de $60 \mathrm{~W}, 75 \mathrm{~W}$, entre otros. Para la adquisición de los datos se debe considerar el inicio de la prueba y todas las mediciones de los sensores instalados en el equipo. Luego, se 
debe esperar el tiempo necesario para el equilibrio térmico en tiempo real, el gradiente de temperatura. En estas pruebas es necesario esperar alrededor de cuarenta y cinco minutos para lograr la estabilidad de la temperatura establecida. Se debe tomar en consideración la medición de espesor del equipo de prueba y aislar toda la zona de trabajo del equipo para disminuir la perdida de calor.

\subsection{Arduino Genuino UNO y sensor DHT22}

El Arduino empleado durante el estudio consiste en una placa electrónica basada en el microcontrolador ATmega328,que cuenta con 14 entradas/salidas digitales, de las cuales 6 se pueden utilizar como salidas PWM (modulación por ancho de pulsos) y otras 6 son entradas análogas. La placa incluye todo lo necesario para que el microcontrolador haga su trabajo, basta conectarla a un ordenador con un cable USB o con una fuente de alimentación externa [6]. El DHT22 es un sensor digital de temperatura y humedad relativa de buen rendimiento y bajo costo. Integra un sensor capacitivo de humedad y un termistor para medir el aire circundante, y muestra los datos mediante una señal digital en el pin de datos (no posee salida analógica). Este sensor ha sido empleado en aplicaciones de control automático de temperatura, aire acondicionado y monitoreo ambiental en agricultura.

A nivel de software se dispone de librerías para Arduino con soporte para el protocolo "Single bus". En cuanto al hardware, solo es necesario conectar el pin VCC de alimentación a 3-5V, el pin GND a Tierra $(0 \mathrm{~V})$ y el pin de datos a un pin digital en nuestro Arduino. Con este sensor se pueden obtener nuevos datos cada 2 segundos. Cada sensor es calibrado en fábrica para obtener unos coeficientes de calibración grabados en su memoria OTP, asegurando alta estabilidad y fiabilidad a lo largo del tiempo.

\subsection{Cámara termográfica}

Se utilizó una cámara de imagen térmica marca Fluke Ti110, la cual posee un sistema de enfoque exclusivo IROptiFlex ${ }^{\mathrm{TM}}$, el cual garantiza un enfoque correcto de las imágenes a partir de una distancia de 1.2 metros (4 pies) para obtener una claridad de la imagen óptima y comodidad en la exploración.

Utilizamos la IR Fusión, en donde una ventana de imagen IR aparece rodeada por un marco fino y visible, que sirve como referencia con el entorno. Esta cámara posee otras funciones como el SmartView el cual permite ver imágenes en forma de retrato, AutoBlend, que combina imágenes visuales e infrarrojas para generar una sola imagen para localizar los puntos de alta temperatura. Este aparato se utilizó para conocer la temperatura de la superficie exterior de las muestras ensayadas.

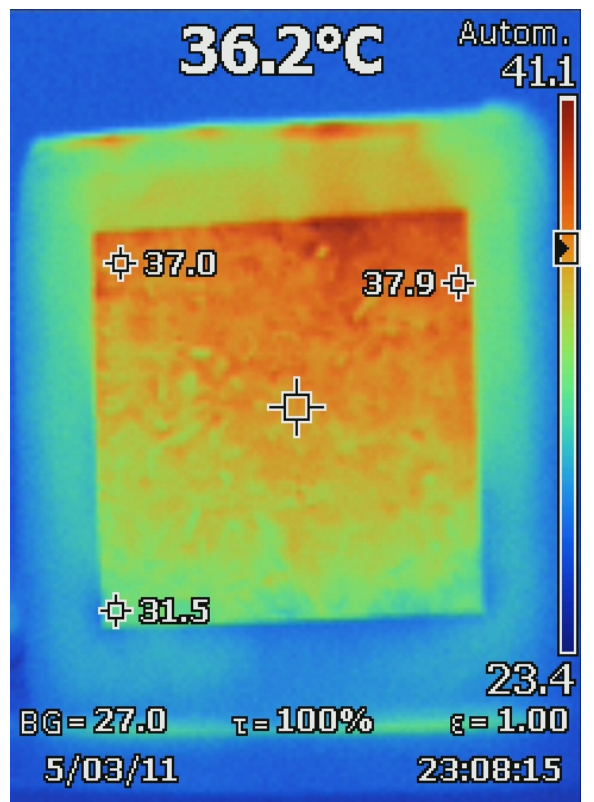

Figura 2. Fotografía térmica de la superficie exterior de una placa ensayada en la caja de Conductividad Térmica.

\section{Resultados}

Obtener el valor de la conductividad térmica se utilizó la ecuación de Fourier para conducción de calor [5]:

$$
\begin{gathered}
\dot{Q}=-K A \frac{\Delta T}{\Delta X} \\
\Delta T=T_{\text {int }}-T_{\text {ext }}
\end{gathered}
$$

En donde $\dot{Q}$ representa el calor transmitido por unidad de tiempo (W), $K$ es el coeficiente de conductividad térmica del material $(\mathrm{W} / \mathrm{mK}), A$ es el área de la superficie en contacto en metros, $\Delta T$ la diferencia de temperatura $\left({ }^{\circ} \mathrm{C}\right)$ y $\Delta X$ el espesor del material en metros. El calor como forma de la energía que se puede extraer de un lado a otro, es el resultado de la diferencia de temperatura, tal y como se expresa en la ecuación (2), donde el calor se transfiere de la zona de alta temperatura a la zona de temperatura menor. En este caso de estudio, la temperatura interior $\left(\mathrm{T}_{\mathrm{int}}\right)$ representa la temperatura de la bombilla medida en el interior de la caja y $\mathrm{T}_{\text {ext }}$ es la temperatura en el exterior. Las variables estudiadas son las temperaturas interior y exterior, mientras se consideran constantes el calor transmitido, el área y el espesor. De la ecuación (1) se despeja el coeficiente de conductividad térmica del material $(K)$, para la definición de su potencial de aislamiento.

En la tabla 1, se muestran los valores de conductividad térmica obtenidos para los materiales ensayados. 
Tabla 1. Conductividades térmicas obtenidas a partir del medidor de conductividad térmica

\begin{tabular}{|l|c|c|c|}
\hline $\begin{array}{c}\text { Material } \\
\text { Ensayado }\end{array}$ & $\begin{array}{c}\text { Temperatura } \\
\text { interior } \\
\text { promedio } \\
\mathbf{T}_{\text {int }}\left({ }^{\mathbf{0}} \mathbf{C}\right)\end{array}$ & $\begin{array}{c}\text { Temperatura } \\
\text { exterior } \\
\text { promedio } \\
\mathbf{T}_{\text {ext }}\left({ }^{\mathbf{0}} \mathbf{C}\right)\end{array}$ & $\begin{array}{c}\text { Conductividad } \\
\text { térmica } \boldsymbol{K} \\
(\mathbf{W} / \mathbf{m K})\end{array}$ \\
\hline $\begin{array}{l}\text { Paja de } \\
\text { arroz con } \\
\text { almidón } \\
\text { de yuca }\end{array}$ & 252.82 & 34.58 & 0.050 \\
\hline $\begin{array}{l}\text { Fibra de } \\
\text { coco con } \\
\text { almidón } \\
\text { de yuca }\end{array}$ & 194.68 & 29.62 & 0.065 \\
\hline $\begin{array}{l}\text { Bagazo de } \\
\text { caña con } \\
\text { almidón } \\
\text { de yuca }\end{array}$ & 224.1 & 28.54 & 0.055 \\
\hline
\end{tabular}

\section{Discusión de Resultados}

Durante la fabricación de los 3 paneles a base de paja de arroz, estopa de coco y bagazo de caña, aglomeradas con almidón de yuca, en donde se tuvo inconvenientes a la hora del proceso de fabricación, por ejemplo a la hora de mezclar el aglomerante con el material, no se conocía la composición necesaria para que el material quedara compacto. Al investigar y conocer el porcentaje de composición para lograr la compactación, se procedió a realizar la mezcla de estos materiales [8]. Como ventaja, podemos mencionar el molde para la fabricación de los paneles. A partir de este molde sencillo, se pueden hacer los paneles con cualquier material natural.

El secado de las láminas se hizo de forma natural, de la experiencia realizada se puede explorar alternativas de procedimiento para el secado del material, y de esta forma asegurar un material que no se degrade tan fácilmente. Se puede comentar que las tres pruebas que presentaron densidades bajas y facilidad de moldeo.

Se realizaron pruebas de conductividad térmica para 3 tipos de materiales distintos, aglomerados con almidón de yuca. De acuerdo con las referencias consultadas, para materiales aislantes se requieren valores de conductividad térmica menores de $0.085 \mathrm{~W} / \mathrm{m} \mathrm{K}$ [8-9]. En este sentido los tres materiales ensayados pueden ser considerados como materiales aislantes [9-11].

\section{Conclusiones}

Del análisis de los resultados obtenidos, se puede decir que los materiales naturales utilizados demostraron conductividad térmica baja, y que se consideran como valores adecuados para aislar térmicamente. Los valores de conductividad térmica entran en el rango de aislamiento térmico que va desde 0.020 $\frac{W}{m \cdot K}$ hasta $0.085 \frac{W}{m \cdot K}$ según la bibliografía consultada.

La realización de estos materiales contribuye con el medio ambiente, y a su vez con el aprovechamiento de residuos agroindustriales, dando cabida al reciclaje y reutilización de residuos que normalmente son considerados como desecho, dándoles un valor agregado.

La temática de materiales naturales como aislantes térmicos se constituye en una línea de investigación de oportunidad, desde el punto de vista de sus propiedades competitivas.

\section{AGRADECIMIENTO}

Este proyecto forma parte del proyecto ITE18-R2-016: "Carbonización de biomasa: aprovechamiento de residuos agrícolas para el mejoramiento de las propiedades fisicoquímicas del suelo en el área de cultivo", el que es financiado por la Secretaria Nacional de Ciencias, Tecnología e Innovación (SENACYT).

\section{REFERENCIAS}

[1] "Importancia del análisis de transferencia de calor dependiente del tiempo en la evaluación del desempeño térmico de la envolvente de una edificación," México, 2009.

[2] M. AMBIENTE, "Estrategia Nacional de Cambi o Climático de Panamá," Mi Ambiente, 12 junio 2015. [En línea]. Available: http://www.miambiente.gob.pa/images/stories/documentos_CC/ Esp_Info_V.1_ENCCP_15.12.2015.pdf. [Jun.1,2019].

[3] A. García, "Diseño de sistema multidimensional de captura y análisis de datos muestreados basado en sistemas embebidos de bajo costo y código abierto," UTP, Panamá, 2016.

[4] R. Carvajal, J. Robles, J. Solís, y J. Vargas, "Sistema de análisis energético y de temperatura de las ventanas de un aula de clase con y sin aislamiento térmico", Rev-RIC, vol. 4, n 2, pp. 26-30, abr. 2019.

[5] J. Gutiérrez and C. Cadena, "Aislamiento térmico producido a partir de cascarilla de arroz aglomerada utilizando almidón producido con saccharomyces cerevisiae." 2013, pp. 139-143.

[6] A. Canto, "Aislante Termico a base de materiales organicos" Revista de iniciación Científica, vol. 4, pp. 48-51, 2018.

[7] ASTM C177-19, Método de prueba estándar para mediciones de flujo de calor en estado estacionario y propiedades de transmisión térmica por medio del aparato de placa de protección en caliente, ASTM International, West Conshohocken, PA, 2019, www.astm.org.

[8] P. e. Universal, "El almidón de yuca funciona como sustituto de la harina de trigo," 5 septiembre 2016. [En línea]. Available: http://www.eluniversal.com/noticias/estilo-vida/almidon-yucafunciona-como-sustituto-harina-trigo_504559.

[9] O. A. d. Olmo, "El bagazo de la caña de azúcar," [En línea]. Available:

karin.fq.uh.cu/acc/2016/CIENCIAS_TECNICAS/032/New/.../P arte\%20V.pdf.

[10] Barnacork, "Rollos de fibra de coco," [En línea]. Available: http://www.barnacork.com/aislamientos/aislamientos/rollos-defibra-de-coco.html.

[11] Y. A. Cengel, Transferencia de calor y masa, McGraw hill. 